\title{
Multiband Planar Inverted-F antenna Employing Rectangular SRR for UMTS and WiMax/WiFi Applications
}

\author{
G. Viswanadh Raviteja \\ Assistant Professor \\ Department of ECE \\ ANITS, Visakhapatnam, India
}

\author{
Valluri Rajya Lakshmi \\ Professor \\ Department of ECE \\ ANITS, Visakhapatnam, India
}

\author{
N. Sravanti Reddy \\ Department of ECE \\ ANITS \\ Visakhapatnam, India
}

\begin{abstract}
An improved PIFA antenna is proposed in this paper. This antenna is with ground dimensions of $40 \times 60$ (in $\mathrm{mm}$ ) and a top conducting plate of $20 \times 10(\mathrm{~mm})$ is considered. The proposed design is targeted to achieve multiband characteristics. For this purpose, the use of rectangular split ring resonator (R-SRR) is taken into consideration. The simulated results showed good S11 return loss characteristics at three frequencies $2.21 \mathrm{GHz}, 3.7 \mathrm{GHz}$ and $5.23 \mathrm{GHz}$ with gain values in $5.41 \mathrm{~dB}, 2.6 \mathrm{~dB}$ and $6.91 \mathrm{~dB}$ respectively. These frequencies are best applied for UMTS $3 \mathrm{G}$ expansion band $(1.9 \mathrm{GHz}-2.2 \mathrm{GHz})$, WiMax $(3.3 \mathrm{GHz}-3.8 \mathrm{GHz})$, WiFi $(4.9 \mathrm{GHz}-5.9 \mathrm{GHz})$ applications.
\end{abstract}

\section{Keywords}

Planar Inverted F antenna, Split ring resonator, WiMax, WiFi.

\section{INTRODUCTION}

Wireless communications nowadays is an integral part of dayto-day life. Over the past decade, demand for faster wireless systems gained much importance [1]. In this regard, there is also tremendous growth in the mobile phone industry. This industry opened plenty of research to antenna designers [2]. One of the important aspect with respect to handheld devices is their size and volume. This is due to the fact that, development in this particular area is to design devices with more compact size. Also, there is a need to address more applications and features in these handheld devices such as GSM 900, GSM 1800, WiFi, WiMax, etc. All these factors led to the design of antennas which are small in size yet performing wise efficient [3]. In recent years, planar inverted $\mathrm{F}$ antenna gained much interest for mobile phone applications [4-7]. These antennas are widely used due to their low profile, efficient performance, and ease of fabrication. Numbers of PIFA configurations are proposed to address both single band and multiband operations. Introduction of slots, meandered shapes and truncated corners are discussed in [8-9]. On the other hand, it is important to note that the overall volume should not exceed the acceptable range and the antenna should remain in compact size [10].

In this paper Section 1 deals with the introduction to PIFA antenna, Section 2 gives the proposed antenna structure with rectangular split ring resonator (R-SRR), Section 3 deals with the simulation results and Section 4 finally concludes the paper.

\section{ANTENNA DESIGN STRUCTURE}

The PIFA structure is shown in Figure 1. The ground plane dimensions are considered to be $40 \mathrm{~mm} \times 60 \mathrm{~mm}$ (X and $\mathrm{Y}$ dimensions). Shorting plate with a width (along $\mathrm{X}$ dimension) is taken as $5 \mathrm{~mm}$ and the height as $3.17 \mathrm{~mm}$. Above the ground, a dielectric substrate is placed with material as FR4 epoxy whose dielectric constant is 4.3 and loss tangent 0.02 . From a height of $5 \mathrm{~mm}$ from the ground plane, a conducting plate is placed with dimensions of $20 \times 10$ (in mm) along the $\mathrm{X}$ and $\mathrm{Y}$ dimensions. For the considered PIFA structure, coaxial feeding is provided with the radius of the circle (wave port) as $0.5 \mathrm{~mm}$. To achieve the multiband characteristics for the considered PIFA, a rectangular split ring resonator (RSRR) is employed. Previously, complementary SRR were used in PIFA [11-12]. But in this paper, a rectangular SRR is proposed. The dimensions for the R-SRR were $16 \mathrm{~mm}$ (along $\mathrm{X}$ dimension) and $6 \mathrm{~mm}$ (along $\mathrm{Y}$ dimension) for the outer rectangular ring and $13 \mathrm{~mm}$ (along $\mathrm{X}$ dimension) for the inner ring.

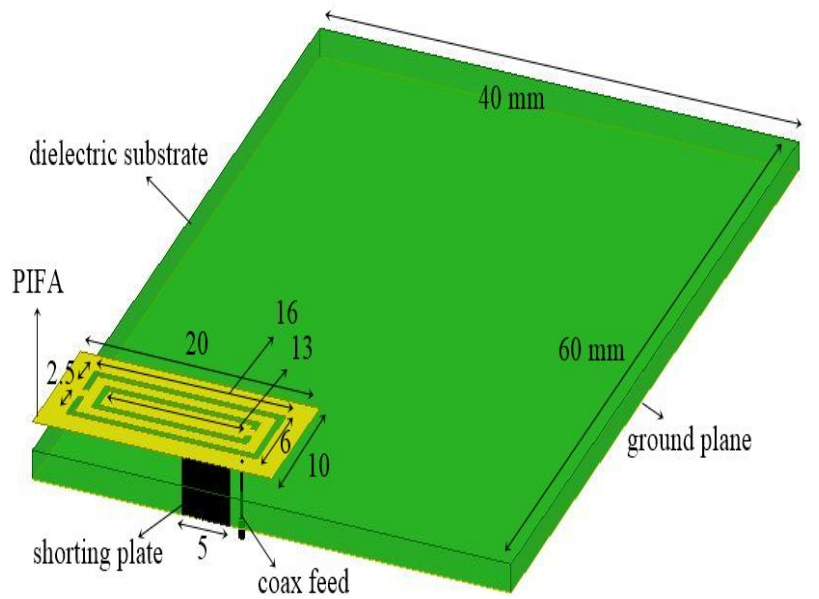

Figure 1. Proposed PIFA with Rectangular Split ring resonator (R-SRR)

The dimensions of the outer and inner rectangular ring, the feed position, the dimensions and the position of the shorting plate were optimized to get the desired result.

\section{RESULTS AND DISCUSSIONS}

The simulations were carried using HFSS simulation software. Firstly, the S11 (return loss) parameter plot is simulated. This is shown in Figure 2.

From the figure 2 , for $2.215 \mathrm{GHz}$ frequency the $\mathrm{S} 11$ was found to be $-20.25 \mathrm{~dB}$, for $3.7 \mathrm{GHz}$ the $\mathrm{S} 11$ was $-14.44 \mathrm{~dB}$ and for $5.23 \mathrm{GHz}$ the return loss was found to be $-26.28 \mathrm{~dB}$. 


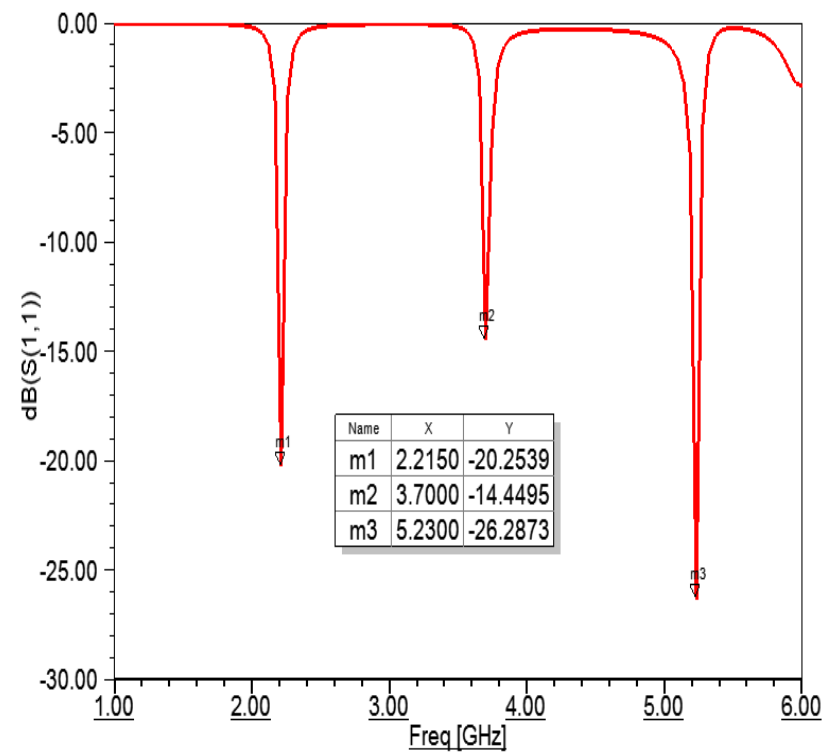

Figure 2. Return loss plot for the proposed PIFA antenna with R-SRR

Secondly, the VSWR plot is shown in Figure 3. In general, the VSWR should be less than 2 (VSWR < 2). From the plot, it is evident that the VSWR results for the three resonant frequencies are less than 2 .

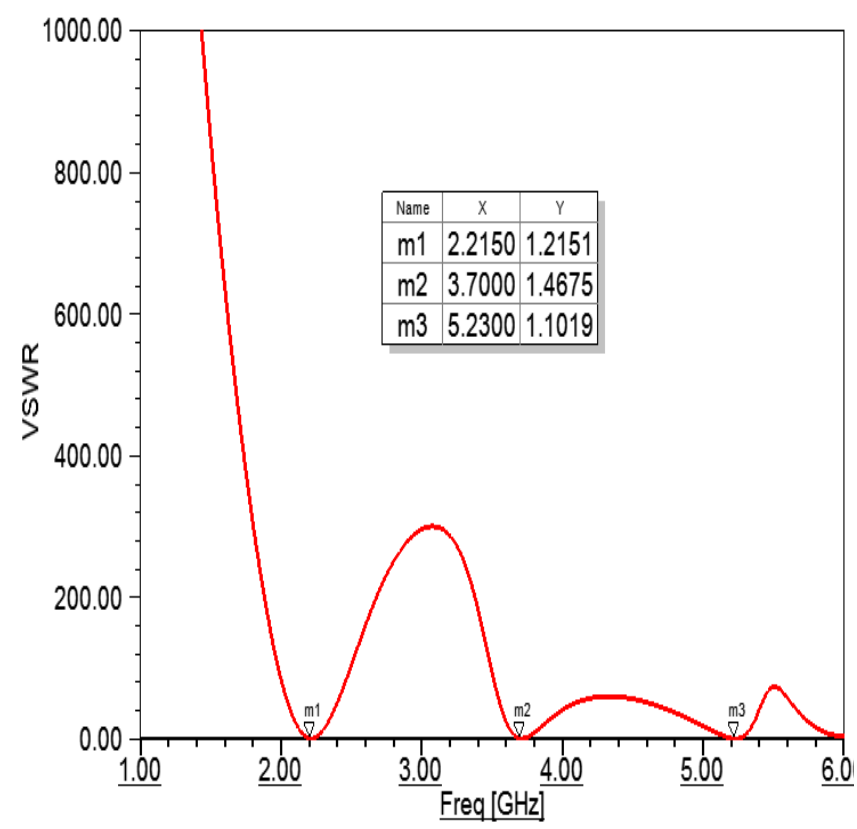

Figure 3. VSWR plot for the Proposed PIFA with R-SRR

Finally, the 3 dimensional gain plots are considered in figures 4,5 and 6 . All the three operating frequencies at $2.2 \mathrm{GHz}, 3.7$ $\mathrm{GHz}$ and $5.23 \mathrm{GHz}$ showed omnidirectional characteristics. Consequently, the 2 dimensional gain plots are also shown in figures 7,8 , and 9 .
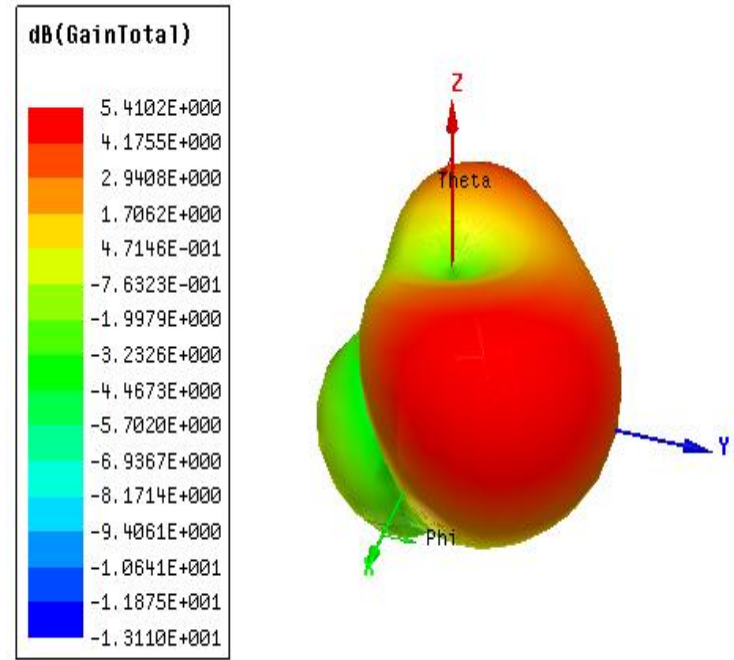

Figure 4. 3D gain plot at $2.21 \mathrm{GHz}$ frequency
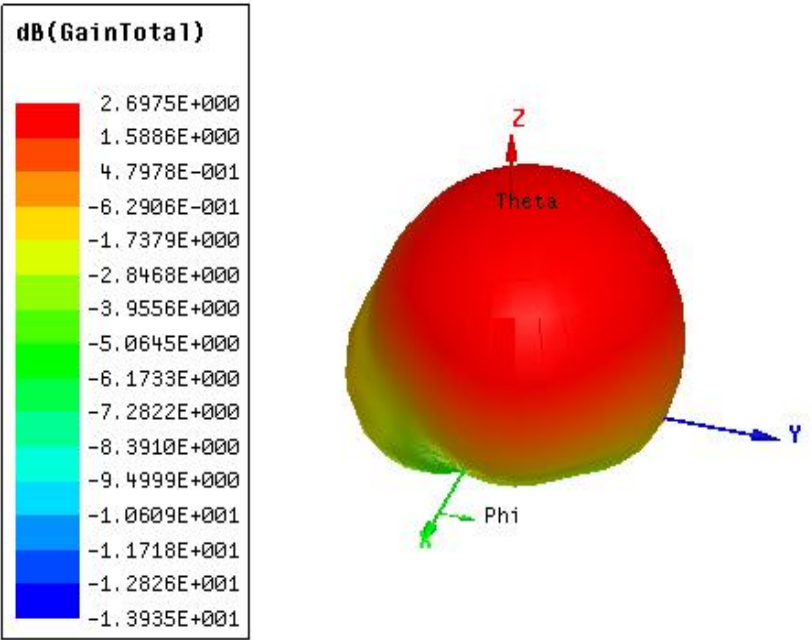

Figure 5. 3D gain plot at 3.7 GHz frequency
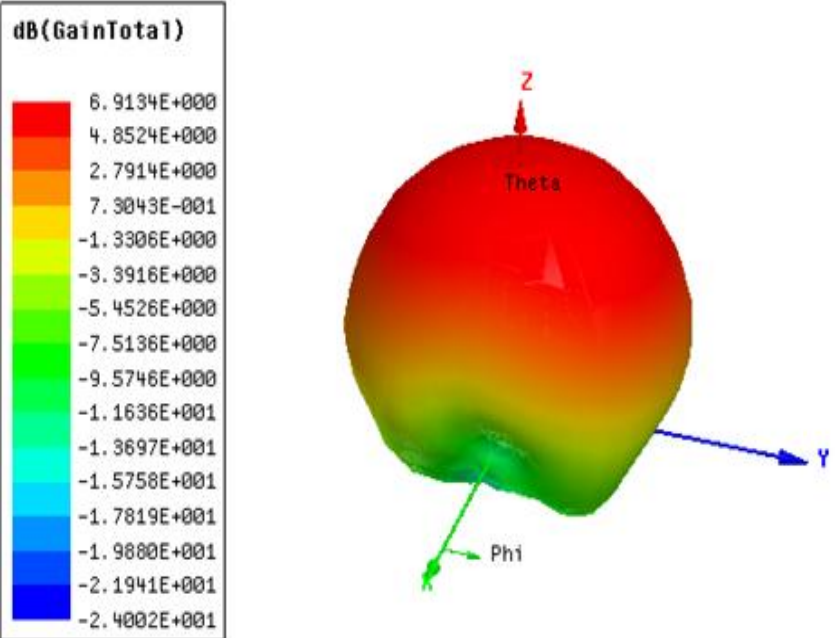

Figure 6. 3D gain plot at 5.23 GHz frequency 


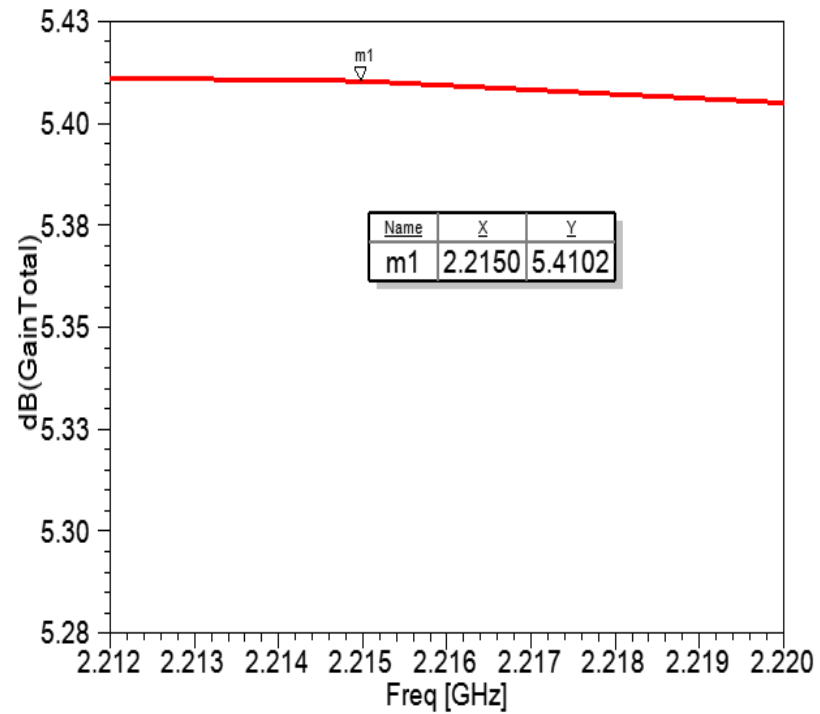

Figure 7. 2D gain plot at 2.21 GHz frequency

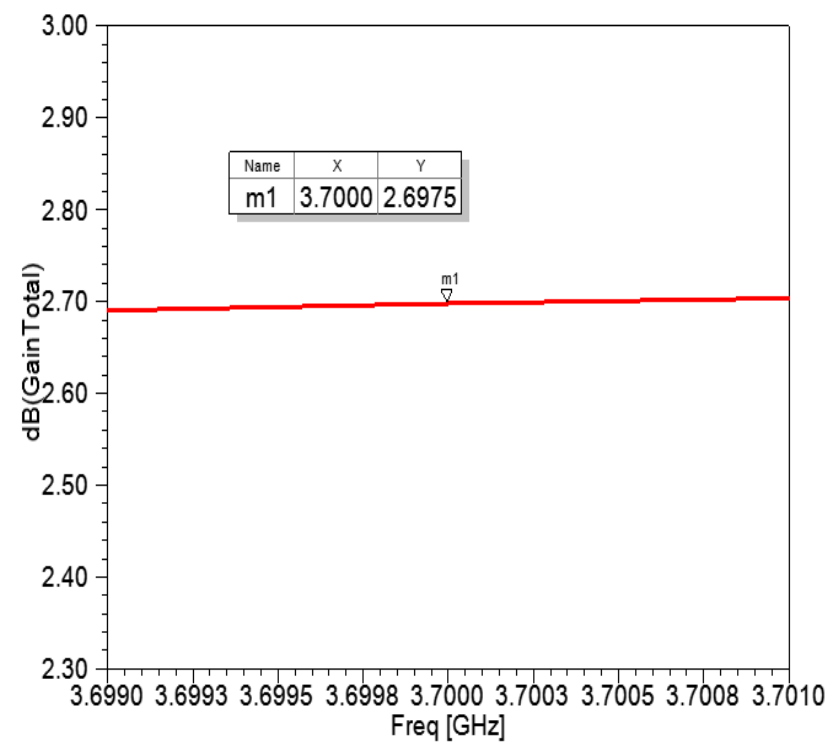

Figure 8. 2D gain plot at $3.7 \mathrm{GHz}$ frequency

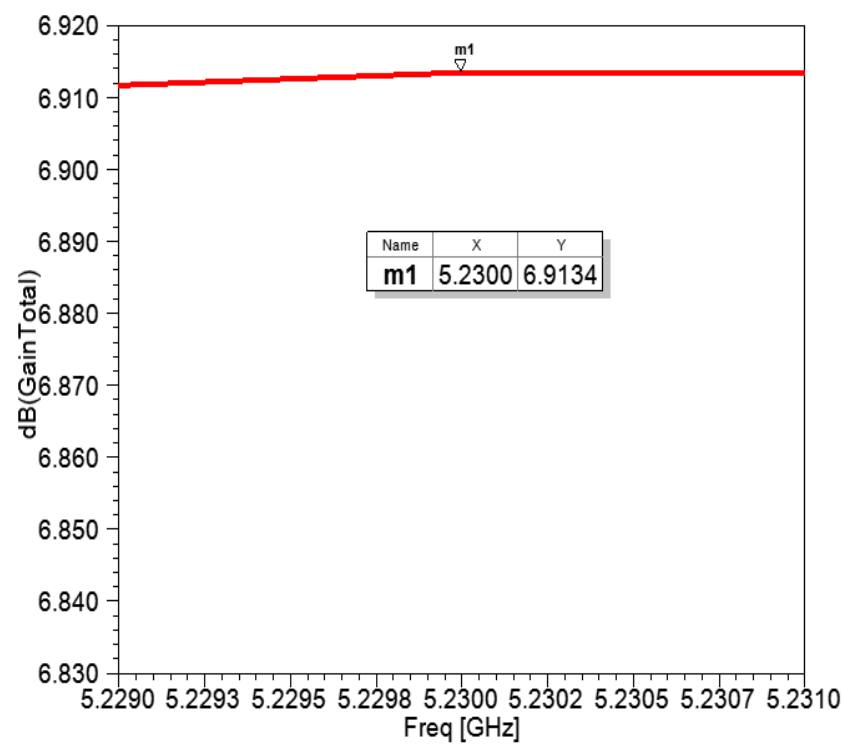

Figure 9. 2D gain plot at 5.23 GHz frequency
Table 1. Different characteristic parameters for proposed PIFA

\begin{tabular}{|c|c|c|c|c|}
\hline S.No & $\begin{array}{c}\text { Antenna } \\
\text { Parameter }\end{array}$ & $\mathbf{1}^{\text {st }}$ Band & $\mathbf{2}^{\text {nd }}$ Band & $\mathbf{3}^{\text {rd }}$ Band \\
\hline 1. & $\begin{array}{c}\text { Resonant } \\
\text { Frequency } \\
(\mathbf{G H z})\end{array}$ & $2.21 \mathrm{GHz}$ & $3.7 \mathrm{GHz}$ & $5.23 \mathrm{GHz}$ \\
\hline 2. & $\mathbf{S 1 1}(\mathbf{d B})$ & $-20.25 \mathrm{~dB}$ & $-14.44 \mathrm{~dB}$ & $-26.28 \mathrm{~dB}$ \\
\hline 3. & VSWR & 1.21 & 1.46 & 1.10 \\
\hline 4. & Gain (dB) & $5.41 \mathrm{~dB}$ & $3.6 \mathrm{~dB}$ & $6.91 \mathrm{~dB}$ \\
\hline
\end{tabular}

\section{CONCLUSION}

The proposed PIFA employing rectangular split ring resonator (R-SRR) structure achieved multiband characteristics at 2.21 $\mathrm{GHz}, 3.7 \mathrm{GHz}$ and $5.23 \mathrm{GHz}$. The $\mathrm{S} 11$ parameters were found out to be $-20.25 \mathrm{~dB},-14.44 \mathrm{~dB}$ and $-26.28 \mathrm{~dB}$. The gain values were also decent. Therefore, the proposed PIFA can be used for UMTS 3G expansion band $(1.9 \mathrm{GHz}-2.2 \mathrm{GHz})$, WiMax $(3.3 \mathrm{GHz}-3.8 \mathrm{GHz}), \mathrm{WiFi}(4.9 \mathrm{GHz}-5.9 \mathrm{GHz})$ applications.

\section{REFERENCES}

[1]. Sharma, A., Gangwar, R.P.S. and Chauhan, S.S., 2013. Design and simulation of multiband Planar inverted-F antenna for mobile phone applications. International Journal on Computer Science and Engineering, 5(5), p.317.

[2]. Anguera Pros, J., Cabedo, A., Picher, C., Sanz, I., Ribó, M. and Puente Baliarda, C., 2007. Multiband handset antennas by means of groundplane modification. In 2007 IEEE Antennas and Propagation Society international symposium: Honolulu, HI, 9-15 June 2007 (pp. 12531256). Institute of Electrical and Electronics Engineers (IEEE).

[3]. Anguera, J., Sanz, I., Mumbrú, J. and Puente, C., 2010. Multiband handset antenna with a parallel excitation of PIFA and slot radiators. IEEE Transactions on Antennas and Propagation, 58(2), pp.348-356.

[4]. Abedin, M.F. and Ali, M., 2003. Modifying the ground plane and its effect on planar inverted-F antennas (PIFAs) for mobile phone handsets. IEEE Antennas and Wireless Propagation Letters, 2(1), pp.226-229.

[5]. M. A. Jensen and Y. Rahmat-Samii, "Performance analysis of antennas for hand-held transceivers using FDTD," IEEE Trans. Antennas Propoagat., vol. 42, pp. 1106-1113, Aug. 1994.

[6]. L. Z. Dong, P. S. Hall, and D. Wake, "Dual-frequency planar inverted-F antennas," IEEE Trans. Antennas Propagat., vol. 45, pp. 1451-1458, Oct. 1997.

[7].G. K. H. Lui and R. D. Murch, "Compact dual-frequency PIFA designs using LC resonators," IEEE Trans. Antennas Propagat., vol. 49, pp.1016-1019, July 2001. 
[8].C.-Y.-D. Sim, "Dual and triple-band PIFA design for WLAN applications," Microw. Opt. Technol. Lett., vol. 49, no. 9, pp. 2159-2162, 2007.

[9].P. W. Chan, H. Wong, and E. Yung, "Wideband planar inverted-F antenna with meandering shorting strip," Electron. Lett., vol. 44, no. 6, pp. 395-396, March 13, 2008.

[10]. Bhatti, R.A., Im, Y.T., Choi, J.H., Manh, T.D. and Park, S.O., 2008. Ultrathin planar inverted-F antenna for multistandard handsets. Microwave and Optical Technology Letters, 50(11), pp.2894-2897.
[11]. Lee, Y., Tse, S., Hao, Y. and Parini, C.G., 2007, June. A compact microstrip antenna with improved bandwidth using complementary split-ring resonator (CSRR) loading. In Antennas and Propagation Society International Symposium, 2007 IEEE (pp. 5431-5434). IEEE.

[12]. Sghaier, N., Latrach, L. and Gharsallah, A., 2016. Effect of Complementary Split Ring Resonator Structure on PIFA Antenna. Journal of Microwaves, Optoelectronics and Electromagnetic Applications, 15(3), pp.237-246. 